\begin{tabular}{|l|l|l|}
\hline \multicolumn{2}{|c|}{ PublisherInfo } \\
\hline \hline PublisherName & $:$ & BioMed Central \\
\hline \hline PublisherLocation & $:$ & London \\
\hline \hline PublisherImprintName & $:$ & BioMed Central \\
\hline \hline
\end{tabular}

\title{
Decoding Cryptosporidium
}

\begin{tabular}{|l|l|l||}
\hline \multicolumn{2}{|c|}{ ArticleInfo } \\
\hline \hline ArticleID & $:$ & 4929 \\
\hline \hline ArticleDOI & $:$ & $10.1186 /$ gb-spotlight-20040329-01 \\
\hline \hline ArticleCitationID & $:$ & spotlight-20040329-01 \\
\hline \hline ArticleSequenceNumber & $:$ & 281 \\
\hline \hline ArticleCategory & $:$ & Research news \\
\hline ArticleFirstPage & $:$ & 1 \\
\hline \hline ArticleLastPage & $:$ & 3 \\
\hline \hline & & RegistrationDate : 2004-3-29 \\
\hline ArticleHistory & $:$ & OnlineDate \\
\hline \hline ArticleCopyright & $:$ & BioMed Central Ltd2004-3-29 \\
\hline \hline ArticleGrants & $:$ & \\
\hline \hline ArticleContext & $:$ & 130594411 \\
\hline \hline
\end{tabular}




\section{Helen Dell}

Email: helen.dell@absw.org.uk

Analysis of the complete genome sequence of Cryptosporidium parvum, published in the March 26 Science, reveals why this parasite has proven so notoriously difficult to treat effectively - it lacks many of the proteins targeted by current antiparasitic drugs.

C. parvum is a water- and food-borne pathogen causing acute gastrointestinal disease in healthy people, but it can cause a life-threatening chronic severe diarrhea in those who are malnourished or immunocompromised. "Despite intensive efforts over the past 20 years, there is currently no effective therapy for treating or preventing C. parvum infection in humans," said lead author Mitch Abrahamsen, of the University of Minnesota College of Medicine.

Unlike many parasitic diseases, cryptosporidiosis is not just limited to the developing world - it is a global problem. In 1993, a major outbreak in Milwaukee infected more than 400,000 people, including about half of Milwaukee's residents with AIDS, nearly $70 \%$ of whom died within 6 months.

The ability of cryptosporidiosis to cause such massive outbreaks and its resistance to standard water treatment regimens have caused concern over the potential use of C. parvum as an agent of bioterrorism, and the US Centers for Disease Control now lists it as a category B pathogen, together with Escherichia coli and Salmonella.

The genome provides the basis for understanding the mechanisms by which the organism causes disease and what causes the differences in virulence and host specificity displayed by different isolates. Abrahamsen hopes that it will point the way to effective drug targets. "This analysis has identified several biochemical pathways with specific enzymes that appear to be more similar to plants and bacteria than the mammalian versions, providing a wide range of new therapeutic targets," he told us.

Now that the entire sequence is available, studies can begin the comparison of molecular drug targets and many aspects of the biology of cryptosporidia with other related species, such as Toxoplasma gondii and the malarial parasite Plasmodium falciparum, said Rima McLeod, a parasitologist at the University of Chicago, who was not involved in the study. "This is very important work," she said.

The most striking difference between Cryptosporidium and its close relatives is the lack of an apicoplast, an organelle specific to this group of parasites that originated from an endocytosed alga. In addition, the $C$. parvum mitochondrial genome is very much reduced. These differences explain why some drugs that have worked on other apicomplexan parasites fail when it comes to treating cryptosporidial infection, according to Boris Striepen, of the University of Georgia's Center for Tropical and Emerging Diseases.

"In retrospect, if you look at the targets that are usually hit in these apicomplexan parasites, either the target enzyme is plainly not there in Cryptosporidium or it is highly divergent," said Striepen, who was not involved in the study. For example, several antibiotics that are commonly used to treat toxoplasmosis target the apicoplast.

To Striepen, the most important finding from the genome sequence is how streamlined its metabolism is. "Biosynthesis is reduced to practically nothing... They completely depend on salvage for most of the 
molecules they use," he said. This should make them vulnerable to drugs that destroy the parasites' scavenging systems, and Striepen is currently working to disable the enzymes that import nucleotides into the organism.

"Now we have a new list of targets to test. We are no longer blindfolded - our efforts can be much more directed and can focus on metabolically appropriate targets," Striepen said.

\section{References}

1. Science, [http://www.sciencemag.org/]

2. Mitchell Abrahamsen, [http://128.101.246.6/research/mvb/faculty/abrahamsen.htm]

3. Massive outbreak of waterborne cryptosporidium infection in Milwaukee, Wisconsin: recurrence of illness and risk of secondary transmission

4. Clinical and epidemiologic features of a massive waterborne outbreak of cryptosporidiosis in persons with HIV infection

5. Cryptosporidiosis, Parasitic Disease Information, US Centers for Disease Control, [http://www.cdc.gov/ncidod/dpd/parasites/cryptosporidiosis/default.htm]

6. Rima McLeod, [http://biomed.bsd.uchicago.edu/faculty/mcleod.html]

7. The apicoplast: a plastid in Plasmodium falciparum and other apicomplexan parasites

8. Boris Striepen, [http://webs.cb.uga.edu/ striepen/]

9. Gene transfer in the evolution of parasite nucleotide biosynthesis

This PDF file was created after publication. 